\section{RSP}

http://www.rsp.fsp.usp.br/
Revista de Saúde Pública

\title{
Association between cigarette use and adolescents' behavior
}

\author{
Jamile Francelino Cruz' iD, Jonathan Lopes de Lisboa" iD, Patricia Maria Pereira de Araújo \\ Zarzar" (iD, Carolina da Franca Bandeira Ferreira Santos"' (iD) Paula Andréa de Melo Valença'"I iD, \\ Valdenice Aparecida de Menezes ${ }^{\mathrm{III}}$ (ID, Viviane Colares ${ }^{\mathrm{III}, \mathrm{IV}}$ (iD) \\ I Universidade de Pernambuco. Faculdade de Odontologia. Mestrado em Hebiatria. Camaragibe, PE, Brasil \\ " Universidade Federal de Minas Gerais. Faculdade de Odontologia. Belo Horizonte, MG, Brasil \\ III Universidade de Pernambuco. Faculdade de Odontologia. Camaragibe, PE, Brasil \\ Iv Universidade Federal de Pernambuco. Departamento de Clínica e Odontologia Preventiva. Recife, PE, Brasil
}

\section{Correspondence:}

Viviane Colares

Universidade de Pernambuco

Av. Gov. Agamenon Magalhães -

Santo Amaro, Recife - PE, 50100-010

E-mail: viviane.colares@upe.br

Received: Feb 25, 2019

Approved: Aug 29, 2019

How to cite: Cruz JF, Lisboa JL, Zarzar PMPA, Santos CFBF, Valença PAM, Menezes VA, Colares V.

Association between cigarette use and adolescents' behavior. Rev

Saude Publica. 2020;54:31.

Copyright: This is an open-access article distributed under the terms of the Creative Commons Attribution License, which permits unrestricted use, distribution, and reproduction in any medium, provided that the original author and source are credited.

\section{ABSTRACT}

OBJECTIVE: To determine the prevalence of cigarette use among adolescents and to identify associated health risk behaviors.

METHODS: This is a cross-sectional study with a representative sample, composed of 1059 adolescents between 13 and 19 years old, enrolled in primary and secondary public schools of Olinda, Pernambuco, in 2014. Information was obtained through self-administered questionnaires (validated version of YRBS 2007). Cigarette experimentation was defined as smoking at least once in life. Adolescents who smoked at least one day within 30 days prior to the survey were considered current smokers. Most students were female and 16 years old or older.

RESULTS: Almost 30\% used it in life and about 10\% smoked within the 30 days before the survey. Suicidal ideation ( $\mathrm{PR}=1.51,95 \% \mathrm{CI} 1.25-1.82)$, alcohol use $(\mathrm{PR}=1.41,95 \% \mathrm{CI} 1.03-1.92)$, marijuana $(\mathrm{PR}=1.64,95 \% \mathrm{CI} 1.37-1.96)$, excessive alcohol consumption $(\mathrm{PR}=1.57,95 \% \mathrm{CI} 1.15-2.16)$ and sexual experience $(\mathrm{PR}=1.78,95 \% \mathrm{CI} 1.43-2.21)$ have increased the risk of using cigarettes. Feelings of sadness ( $\mathrm{PR}=1.70,95 \% \mathrm{CI} 1.22-2.36)$, alcohol use ( $\mathrm{PR}=2.40,95 \% \mathrm{CI} 1.12-5.12)$, excessive alcohol consumption ( $\mathrm{PR}=2.5$, 95\% CI 1.24-5.38), marijuana $(\mathrm{PR}=2.31,95 \% \mathrm{CI} .57-3.39)$ and cocaine $(\mathrm{PR}=1.99,95 \%$ CI.32-3.01) increased the risk of cigarette use within the 30 days before the survey.

CONCLUSIONS: Cigarette use among adolescents from Olinda was high, being considered higher than the national prevalence. Possible factors associated with cigarette use were drug use (alcohol, marijuana, and cocaine) and behaviors related to sexual experience, feelings of sadness and suicidal ideation.

DESCRIPTORS: Adolescent. Smoking, epidemiology. Risk Factors. Health Risk Behaviors. Cross-Sectional Studies. 


\section{INTRODUCTION}

Smoking is the leading cause of preventable death in the world ${ }^{1}$, taking the lives of more than six million people a year and still causing disabling chronic diseases. However, despite the latest efforts to fight against smoking, cigarette smoking continues to be one of the most consumed drugs in Brazil and in the world, including adolescents ${ }^{2}$, who are beginning to have risky behavior earlier and earlier ${ }^{3}$. According to the Pesquisa Nacional de Saúde do Escolar (PeNSE - National School Health Survey), in a study conducted with ninth-grade students, over $30 \%$ of children between 13 and 15 years tried smoking before turning $12^{4}$. This early cigarette experimentation may lead most smokers to become dependent even before reaching adulthood ${ }^{1}$. For this reason, the World Health Organization considers smoking a pediatric disease ${ }^{1}$.

The World Health Organization Framework Convention on Tobacco Control (WHO FCTC) $)^{2}$ was conceived in 2005 to join forces against the tobacco industry, improve population health and save lives. This document was the first public health treaty aimed at the fight against tobacco use in the world, currently counting on the participation of 180 countries, representing more than $90 \%$ of the world population. In 2008 , some measures were implemented by the FCTC members in the fight against smoking around the world, known as MPOWER. They include: monitoring tobacco use and prevention policies; protecting people from tobacco smoke; offering help to quit smoking; warning about the harmful effects of tobacco; reinforcing advertising bans; promotions and sponsorships of tobacco companies; and, finally, raising taxes on tobacco marketing. Currently, more than half of the world's countries have successfully implemented at least one of these measures and have been highly successful at combating and controlling smoking, reducing the number of smokers worldwide. Brazil has already implemented four of these measures ${ }^{2}$.

However, national surveys recently conducted ${ }^{1,5}$ have shown that among adolescents between 13 and 15 years old, both cigarette use in life and within 30 days prior to the survey have remained stable, around $20 \%$ and $6 \%$, respectively. The Northeast is the Brazilian region with the lowest prevalence of cigarette use in life (15\%) and within 30 days prior to the survey (3\%).

Even more alarming, in the 16-17 years old age group, the Brazilian Institute of Geography and Statistics (IBGE) ${ }^{5}$ survey showed a higher overall prevalence of cigarette use in life (30\%) and within 30 days prior to the survey (9\%), when compared with the 13-15 years old age group. Also, a survey conducted in 2010 by the Brazilian Center for Information on Psychotropic Drugs (BCIPD), showed that tobacco is the second most experienced drug among primary and secondary school students in public and private schools in the country, losing only to the consumption of alcohol ${ }^{6}$.

Adolescents are also commonly exposed to other risk behaviors such as involvement in fights, insufficient physical activity, abusive consumption of alcoholic beverages, drug abuse, inadequate feeding, ineffective use of contraceptive methods, and exposure to sexually transmitted diseases ${ }^{3}$. Smoking has also been identified as a marker for mental disorders such as anxiety, depression, and psychosis, or indicate other adverse mental health states such as low self-esteem, behavioral propensity risk, impulsivity, aggressiveness, antisocial personality or emotional instability?

This context highlights the importance of monitoring the health situation and adolescent risk behaviors to provide information that reflects the complexity and dynamics of changes to which this age group is subjected and help in the development of policies that can best fulfill adolescents' needs.

Our study sought to determine the prevalence of cigarette use among adolescents of public schools in Pernambuco and to identify adolescent's risk behaviors associated with this use. 


\section{METHODS}

\section{Study design and sample}

This is a cross-sectional, descriptive and analytical study conducted in the city of Olinda, Pernambuco, between April and August 2014, with adolescents regularly enrolled in primary and secondary education in the state's public schools.

The sample was estimated considering a $95 \%$ confidence interval, an $80 \%$ power, a $50 \%$ prevalence, an 1.5 Odds Ratio and an 1.2 effect of delineation, resulting in a sample size of 980 adolescents. This number was increased by $10 \%$ to compensate for possible losses, resulting in a sample of 1078 adolescents. However, some questionnaires were excluded due to incorrect or incomplete completion, resulting in a final sample of 1,059 adolescents.

Schools were randomly selected through two raffles stratified by school and group. There were 22 schools and 60 groups drawn. In these groups, all students between 13 and 19 years old present on the day of collection and who did not present a cognitive condition that could interfere in the resolution of the questionnaire were invited to participate in the study.

\section{Ethical considerations}

The study was approved by the Research Ethics Committee of the Universidade de Pernambuco (no. 588.996). The permission was obtained from parents or guardians through the informed consent form and from adolescents who agreed to participate by signing the assent term.

\section{Data collect}

The information was obtained from Youth Risk Behavior Survey (YRBS) and applied in classrooms under the supervision of the study team. The YRBS Questionnaire used was validated and translated into Portuguese ${ }^{8}$ and includes questions related to behavior, personal safety, unintentional injuries and violence, feelings of sadness and suicidal ideation, tobacco use, consumption of alcoholic beverages, use of marijuana and other drugs, sexual behavior, body weight, physical activity, bullying, eating habits, and health-related issues ${ }^{9}$. In our study, we used the questions regarding the modules of violence, feelings of sadness and suicidal ideation, use of tobacco, alcohol and other drugs, sexual behavior and attitude related to body weight. Also, some questions were added to determine the sociodemographic, financial and religious profile of this population (age, sex, family income, type of school and religion).

\section{Study variables}

\section{Cigarrette use}

The study outcome on cigarette use was evaluated through the following variables: "Cigarette experimentation" and "current cigarette use." "Cigarette experimentation" was defined as having tried cigarettes at least once in life, evaluated by the question: "Within the last 12 months, have you tried to quit smoking cigarette?" (Answer options: "I did not smoke within the last 12 months," "yes," "no"), dichotomized in no ("I did not smoke within the last 12 months") and yes ("yes," "no"). Teenagers who smoked at least one day within the 30 days prior to the survey were considered current cigarette smokers (current cigarette use). "Current cigarette use" was assessed by the question: "Within the last 30 days, how many days did you smoke cigarettes?" (Answer options: "none," "1 or 2 days," "3 to 5 days," "6 to 9 days," "10 to 19 days," "20 to 29 days" and "all 30 days"), dichotomized in "no" ("none") and "yes" (“1 or 2 days," “3 to 5 days," “6 to 9 days," “10 to 19 days," " 20 to 29 days," “all 30 days").

\section{Violence}

Violence was assessed through the following variables: "Involvement in body fight" and "physical aggression by the partner." "Involvement in body fight" was assessed by the question: 
"Within the last 12 months, how often did you get involved in a body fight?" (Answer options: "none," "1 time," "2 or 3 times," " 4 or 5 times," " 6 or 7 times," " 8 or 9 times," "10 or 11 times," " 12 or more times"), dichotomized in "no" ("none") and "yes" ("1 time," "2 or 3 times," "4 or 5 times," "6 or 7 times," "8 or 9 times," "10 or 11 times," "12 or more times"). "Physical aggression by the partner" was assessed by the question: "Within the last 12 months, did your boyfriend or girlfriend physically assault you with slaps, punches or kicks?" (Answer options: "yes," "no").

\section{Feeling of sadness and suicidal ideation}

Feeling of Sadness and Suicidal Ideation were evaluated through the following variables: "Feeling of Sadness," "Suicidal Thinking" and "Attempted Suicide." "Feeling of sadness" was assessed by the question: "Within the last 12 months, have you felt excessively sad or hopeless on almost every day of a period of 2 or more weeks leading you to stop your normal activities?" (Answer options: "yes," "no"). "Suicidal thinking” was evaluated by the question: "Within the last 12 months, did you ever seriously think about committing suicide (to kill yourself)?" (Answer options: “yes," "no"). The "suicide attempt" was assessed by the question: "Within the last 12 months, how many times have you actually attempted suicide?" (Answer options: "none," "1 time," " 2 or 3 times," " 4 or 5 times," " 6 or more times") dichotomized in "no" ("none") and "yes" ("1 time," “2 or 3 times," “4 or 5 times," “6 or more times").

\section{Drug use}

Drug use was evaluated through the following variables: "Alcohol use," "Binge drinking," "Marijuana use," and "Cocaine use." "Alcohol use" was assessed by the question: "Within the last 30 days, how many days did you drink at least one dose of alcohol?" (Answer options: "none," " 1 or 2 days,' " 3 to 5 days," "6 to 9 days," " 10 to 19 days," "20 to 29 days," "all 30 days"), dichotomized in "no" ("none") and "yes" ("1 or 2 days," "3 to 5 days," "6 to 9 days," "10 to 19 days," "20 to 29 days," "all 30 days"). "Binge drinking" was evaluated by the question: "Within the last 30 days, how many days did you drink 5 or more doses of alcohol on the same occasion?" (Answer option: "none," "1 1 or 2 days,' "3 to 5 days," "6 to 9 days," "10 to 19 days," "20 to 29 days," "all 30 days"), dichotomized in "no" ("none") and "yes" ("1 or 2 days," " 3 to 5 days," "6 to 9 days," "10 to 19 days," "20 to 29 days," "all 30 days"). "Marijuana use” was evaluated by the question: "Within the last 30 days, how many times did you use marijuana?" (Answer options: "none," "1 or 2 times," "3 to 9 times," "10 to 19 times," "20 to 39 times" and "40 or more times"), dichotomized in "no" ("none") and "yes" ("1 or 2 times," "3 to 9 times," "10 to 19 times," "20 to 39 times" and " 40 or more times"). "Cocaine use" was evaluated by the question: "Within the last 30 days, how many times did you use any form of cocaine, including powder, stone or paste?" (Answer options: "none," "1 or 2 times," "3 to 9 times," "10 to 19 times," "20 to 39 times" and " 40 or more times"), dichotomized in "no" ("none") and "yes" ("1 or 2 times," "3 to 9 times," "10 to 19 times," "20 to 39 times" and "40 or more times").

\section{Sexual behavior}

Sexual behavior was evaluated by the variable "Sexual intercourse" and this one was evaluated by the question: "Have you had sexual intercourse?" (Answer option: "yes," "no").

Attitude related to weight

Attitude related to weight was evaluated by the variable "Initiative to change body weight," The "initiative to change body weight" was evaluated by the question: "Have you tried any initiative to change your body weight?" (Answer options: "losing body weight," "gaining body weight," "maintaining body weight" and "I have never taken any initiative to change my body weight"), dichotomized in "no" ("I have never taken any initiative to change my body weight") and "yes" (“losing body weight," "gaining body weight," "maintaining body weight”).

Socioeconomic and sociodemographic characteristics

The socioeconomic characteristics were evaluated by the variables: "Age," "Sex," "Family income," "School type," and "Religion." Age was categorized by cutoff by the median, 
dichotomized at " 15 years old or less" and "16 years old or more." Sex was evaluated with both male and female options. The monthly family income was determined based on the sum of all salaries received by the economically active residents of the household and categorized based on the minimum wage in force in Brazil, as follows: "up to 3 minimum wages," "more than 3 minimum wages" and "I do not know how to inform." The type of school was analyzed by the answers: "Regular," "Semi-Full-time," and "Full-time," categorized under cut-off by the median and dichotomized in "regular" and "semi-integral and integral." The religion was evaluated by the question: "What is your religion?" (Answer options: "none," "Catholic," "Evangelical," "Spiritist," "Afro-Brazilian," and "other"), dichotomized in "no" ("none") and “yes" (“Catholic," “Evangelical," "Spiritist," “Afro-Brazilian,” and “other”).

\section{Statistical analysis}

Data were tabulated in Epidata, version 3.1, using the double-entry resource, to guarantee the reliability of the answers, and then analyzed in SPSS software, version 23.0 for Windows.

Frequency was analyzed to determine the sociodemographic and financial profile of adolescents, the prevalence of cigarette use and their distribution by sex.

In the non-adjusted analysis, the chi-square test was applied to identify health risk behaviors that influenced cigarette use in the population studied, and Fisher's exact test when necessary. We considered a $5 \%$ level of significance.

To verify the magnitude of this association, adjusted analysis was performed through Poisson regression with robust variance and confidence intervals were estimated for prevalence ratio and Wald test. Only variables with a value of $p \leq 0.05$ remained in the regression-adjusted final model.

\section{RESULTS}

Most of the 1,059 adolescents who answered the questionnaire were female (53.4\%), aged 16 years old or older (72.7\%), had a family income of up to 3 minimum wages (54\%), attended regular schools (65.7\%) and followed some religion (72.9\%). Regarding cigarette use, almost $30 \%$ stated having used cigarettes in life, while about $10 \%$ reported using it within the 30 days prior the survey, as shown in Table 1.

Cigarette experimentation and current cigarette use were more prevalent in male adolescents aged 16 years old or over, with family income of more than 3 minimum wages, enrolled in a full-time or a semi-full-time schools, and who did not have a religion. However, only the variables "age" and "religion" were associated with cigarette experimentation (cigarette use in life) and only religion was associated with current cigarette use (at least one day within 30 days prior to the survey), as shown in Table 2 .

Regarding violence-related behaviors, cigarette use in life and within the last 30 days was more frequent in adolescents who engaged in body fighting and suffered physical aggression by the partner. Regarding behaviors related to feeling of sadness and suicidal ideation, those who felt sad and hopeless and who admitted suicidal thoughts and attempt showed a higher prevalence of cigarette use in life and within the 30 days prior to the survey.

In the non-adjusted analysis, we could identify that cigarette use was also more observed in adolescents who drank or admitted binge drinking within the 30 days prior to the survey, as well as among those who admitted having used marijuana or cocaine in the same period. Adolescents who have already had their first sexual intercourse and taken some initiative to change their body weight also showed a higher prevalence of cigarette use. All the aforementioned behaviors had a statistically significant association with cigarette use in life and within the 30 days prior to the survey, as shown in Table 3. 
Table 1. Distribution of adolescents according to socioeconomic, sociodemographic and cigarette use, stratified by sex. Olinda, Brazil, 2014.

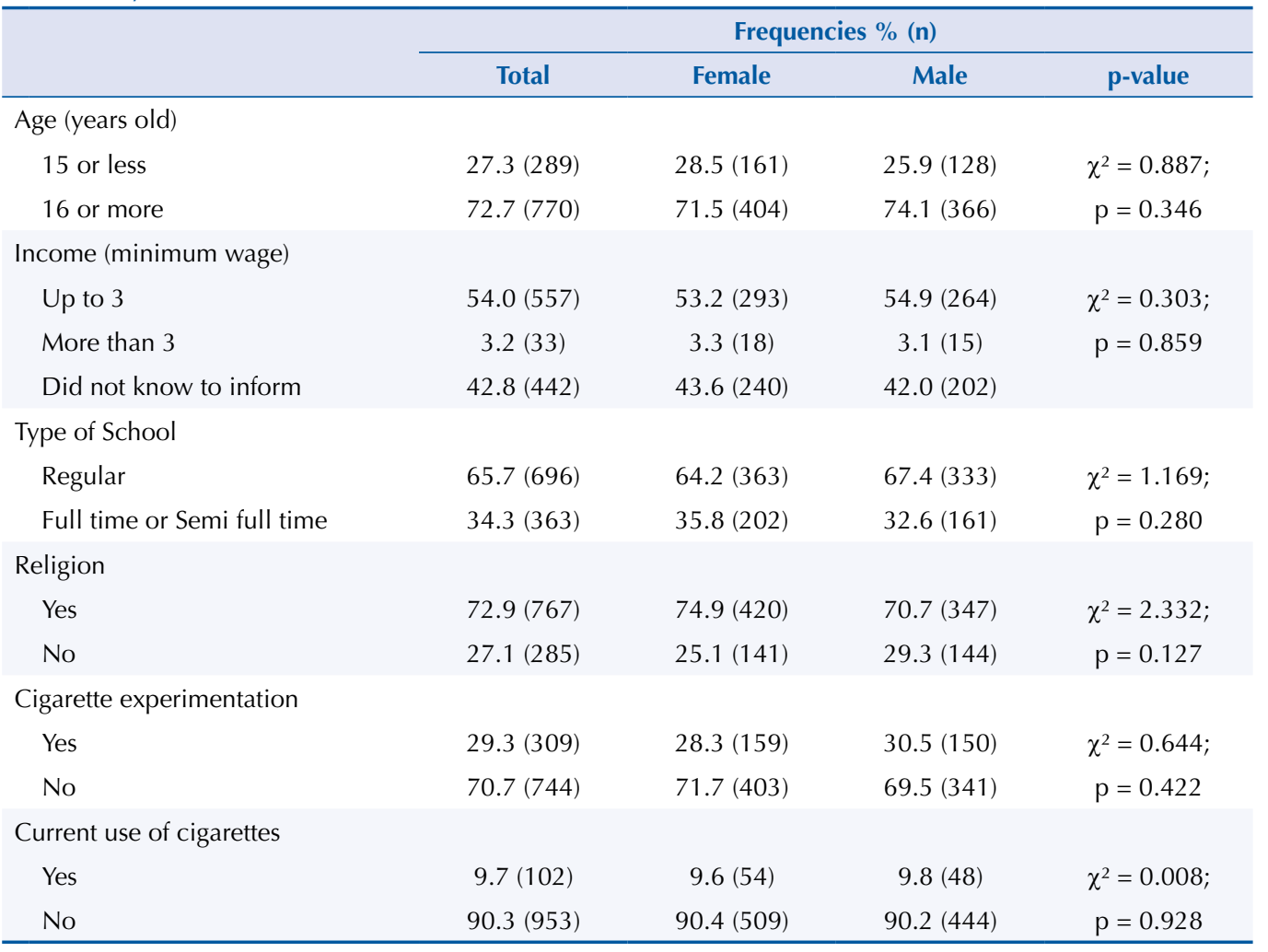

Table 2. Prevalence of cigarette experimentation and current cigarette use according to socio-demographic and socioeconomic characteristics Olinda, Brazil, 2014

\begin{tabular}{|c|c|c|c|c|c|c|c|c|c|c|}
\hline & \multicolumn{4}{|c|}{ Cigarette experimentation } & \multirow{3}{*}{$p$-value } & \multicolumn{4}{|c|}{ Current use of cigarette } & \multirow{3}{*}{$p$-value } \\
\hline & \multicolumn{2}{|c|}{ Yes } & \multicolumn{2}{|c|}{ No } & & \multicolumn{2}{|c|}{ Yes } & \multicolumn{2}{|c|}{ No } & \\
\hline & $\mathbf{N}$ & $\%$ & $\mathbf{N}$ & $\%$ & & $\mathbf{N}$ & $\%$ & $\mathbf{N}$ & $\%$ & \\
\hline \multicolumn{11}{|l|}{ Socioeconomics Characteristics } \\
\hline \multicolumn{11}{|l|}{ Sex } \\
\hline Female & 159 & 28.3 & 403 & 71.7 & $\chi^{2}=0, .644$ & 54 & 9.6 & 509 & 90.4 & $\chi^{2}=0.008$ \\
\hline Male & 150 & 30.5 & 341 & 69.5 & $p=0, .422$ & 48 & 9.8 & 444 & 90.2 & $p=0.928$ \\
\hline \multicolumn{11}{|l|}{ Age (years old) } \\
\hline 15 or $<$ & 59 & 20.5 & 229 & 79.5 & $\chi^{2}=15.004$ & 21 & 7.3 & 268 & 92.7 & $\chi^{2}=2.629$ \\
\hline 16 or $>$ & 250 & 32.7 & 515 & 67.3 & $\mathrm{p}<0.001$ & 81 & 10.6 & 685 & 89.4 & $p=0.105$ \\
\hline \multicolumn{11}{|l|}{ Income (minimum wage) } \\
\hline Up to 3 & 168 & 30.3 & 387 & 69.7 & & 51 & 9.2 & 505 & 90.8 & $\chi^{2}=1.293$ \\
\hline More than 3 & 13 & 41.9 & 18 & 58.1 & $\chi^{2}=3.511$ & 5 & 15.2 & 28 & 84.8 & $p=0.524$ \\
\hline Did not know to inform & 120 & 27.3 & 320 & 72.7 & $p=0.173$ & 42 & 9.5 & 398 & 90.5 & \\
\hline \multicolumn{11}{|l|}{ Type of School } \\
\hline Regular & 194 & 28.0 & 498 & 72.0 & $\chi^{2}=1.671$ & 63 & 9.1 & 631 & 90.9 & $\chi^{2}=0.810$ \\
\hline Full time or Semi full time & 115 & 31.9 & 246 & 68.1 & $p=0.196$ & 39 & 10.8 & 322 & 89.2 & $p=0.368$ \\
\hline \multicolumn{11}{|l|}{ Religion } \\
\hline Yes & 201 & 26.3 & 562 & 73.7 & $\chi^{2}=13.063$ & 65 & 8.5 & 700 & 91.5 & $\chi^{2}=4.233$ \\
\hline No & 107 & 37.8 & 176 & 62.2 & $p<0.001$ & 36 & 12.7 & 247 & 87.3 & p 0.040 \\
\hline
\end{tabular}

In the adjusted analysis, suicidal thoughts ( $\mathrm{PR}=1.51,95 \% \mathrm{CI}: 1.25-1.82)$, alcohol use $(\mathrm{PR}=1.41,95 \% \mathrm{CI}$ : 1.03-1.92), binge drinking ( $\mathrm{PR}=1.57$, 95\%CI: 1.15-2.16), marijuana use (PR $=1.64,95 \% \mathrm{CI}: 1.37-1.96)$ and having sexual intercourse (PR = 1.78; 95\%CI: 1.43-2.21) were considered as risk factors for cigarette use in life. Regarding the cigarette use within the 30 days prior to the survey, this risk was increased in adolescents who presented a 
Table 3. Distribution of cigarette use among adolescents according to health risk behaviors, Olinda, Brazil, 2014.

\begin{tabular}{|c|c|c|c|c|c|c|c|c|c|c|}
\hline & \multicolumn{4}{|c|}{ Cigarette smoking in life } & \multirow{3}{*}{ p-value } & \multicolumn{4}{|c|}{ Cigarette use in the last 30 days } & \multirow{3}{*}{ p-value } \\
\hline & \multicolumn{2}{|c|}{ Yes } & \multicolumn{2}{|c|}{ No } & & \multicolumn{2}{|c|}{ Yes } & \multicolumn{2}{|c|}{ No } & \\
\hline & $\mathbf{N}$ & $\%$ & $\mathbf{N}$ & $\%$ & & $\mathbf{N}$ & $\%$ & $\mathbf{N}$ & $\%$ & \\
\hline \multicolumn{11}{|c|}{ Violence (12 months) } \\
\hline Yes & 113 & 45.2 & 137 & 54.8 & $\chi^{2}=39.749$ & 47 & 18.8 & 203 & 81.2 & $\chi^{2}=31.284$ \\
\hline No & 196 & 24.4 & 607 & 75.6 & $\mathrm{p}<0.001$ & 55 & 6.8 & 750 & 93.2 & $\mathrm{p}<0.001$ \\
\hline \multicolumn{11}{|c|}{ Partner physical aggression } \\
\hline Yes & 31 & 63.3 & 18 & 36.7 & $\chi^{2}=17.397$ & 31 & 63.3 & 18 & 36.7 & $\chi^{2}=9.736$ \\
\hline No & 147 & 33.1 & 297 & 66.9 & $\mathrm{p}<0.001$ & 147 & 33.1 & 297 & 66.9 & $p=0.002$ \\
\hline \multicolumn{11}{|c|}{ Feelings of sadness and suicidal ideation (12 months) } \\
\hline \multicolumn{11}{|c|}{ Feeling Sad } \\
\hline Yes & 112 & 42.7 & 150 & 57.3 & $\chi^{2}=30.088$ & 49 & 18.6 & 214 & 81.4 & $\chi^{2}=32.142$ \\
\hline No & 197 & 24.9 & 593 & 75.1 & $\mathrm{p}<0.001$ & 53 & 6.7 & 738 & 93.3 & $\mathrm{p}<0.001$ \\
\hline \multicolumn{11}{|c|}{ Suicidal thoughts } \\
\hline Yes & 86 & 53.4 & 75 & 46.6 & $\chi^{2}=53.349$ & 37 & 22.8 & 125 & 77.2 & $\chi^{2}=38.749$ \\
\hline No & 222 & 24.9 & 668 & 75.1 & $\mathrm{p}<0.001$ & 64 & 7.2 & 827 & 92.8 & $\mathrm{p}<0.001$ \\
\hline \multicolumn{11}{|c|}{ Suicide attempt } \\
\hline Yes & 44 & 51.8 & 41 & 48.2 & $\chi^{2}=22.383$ & 25 & 29.4 & 60 & 70.6 & $\chi^{2}=41.746$ \\
\hline No & 264 & 27.4 & 700 & 72.6 & $\mathrm{p}<0.001$ & 76 & 7.9 & 890 & 92.1 & $\mathrm{p}<0.001$ \\
\hline \multicolumn{11}{|c|}{ Drug use (30 days) } \\
\hline \multicolumn{11}{|c|}{ Alcohol use } \\
\hline Yes & 171 & 53.6 & 148 & 46.4 & $\chi^{2}=129.275$ & 77 & 24.1 & 243 & 75.9 & $\chi^{2}=108.598$ \\
\hline No & 138 & 18.9 & 594 & 81.1 & $\mathrm{p}<0.001$ & 25 & 3.4 & 708 & 733 & $p<0.001$ \\
\hline \multicolumn{11}{|c|}{ Binge drinking } \\
\hline Yes & 149 & 60.1 & 99 & 39.9 & $\chi^{2}=150.498$ & 72 & 28.8 & 178 & 71.2 & $\chi^{2}=136.693$ \\
\hline No & 157 & 19.6 & 645 & 80.4 & $\mathrm{p}<0.001$ & 30 & 3.7 & 772 & 96.3 & $\mathrm{p}<0.001$ \\
\hline \multicolumn{11}{|c|}{ Marijuana use } \\
\hline Yes & 57 & 85.1 & 10 & 14.9 & $\chi^{2}=107.593$ & 31 & 47.0 & 35 & 53.0 & $\chi^{2}=113.590$ \\
\hline No & 251 & 25.5 & 734 & 74.5 & $\mathrm{p}<0.001$ & 70 & 7.1 & 918 & 92.9 & $\mathrm{p}<0.001$ \\
\hline \multicolumn{11}{|c|}{ Cocaine use } \\
\hline Yes & 11 & 91.7 & 1 & 8.3 & & 9 & 75.0 & 3 & 25.0 & \\
\hline No & 298 & 28.6 & 743 & 71.4 & $\mathrm{p}<0.001^{*}$ & 93 & 8.9 & 950 & 91.1 & $\mathrm{p}<0.001^{*}$ \\
\hline \multicolumn{11}{|c|}{ Sexual Behavior } \\
\hline \multicolumn{11}{|c|}{ Sexual intercourse } \\
\hline Yes & 212 & 43.2 & 279 & 56.8 & $\chi^{2}=85.113$ & 76 & 15.5 & 415 & 84.5 & $\chi^{2}=36.676$ \\
\hline No & 93 & 17.0 & 453 & 83.0 & $\mathrm{p}<0.001$ & 24 & 4.4 & 524 & 95.6 & $\mathrm{p}<0.001$ \\
\hline \multicolumn{11}{|c|}{ Attitude related to weight } \\
\hline \multicolumn{11}{|c|}{ Attitudes to change body weight } \\
\hline Yes & 245 & 31.3 & 539 & 68.8 & $\chi^{2}=5.901$ & 85 & 10.8 & 704 & 89.2 & $\chi^{2}=4.120$ \\
\hline No & 62 & 23.4 & 203 & 76.6 & $p=0.015$ & 17 & 6.5 & 245 & 93.5 & $p=0.042$ \\
\hline
\end{tabular}

* Fisher's Exact Test

feeling of sadness ( $\mathrm{PR}=1.70,95 \% \mathrm{CI}: 1.22-2.36)$, alcohol use (PR $=2.40,95 \% \mathrm{CI}: 1.12-5.12)$, binge drinking ( $\mathrm{PR}=2.58,95 \% \mathrm{CI}: 1.24-5.38)$, marijuana use ( $\mathrm{PR}=2.31,95 \% \mathrm{CI}: 1.57-3.39)$ and cocaine use (PR $=1.99 ; 95 \% \mathrm{CI}: 1.32-3.01)$, as shown in Table 4.

\section{DISCUSSION}

Adolescence is an impacted phase of life, in which, as a result of the discoveries, the anxieties, due to the need to explore the unknown and to venture without worrying about the consequences, adolescents are led to adopt risk behaviors such as cigarette use ${ }^{10}$. 
Table 4. Poisson adjusted final model for cigarette use in life and in the last 30 days and independent variables. Olinda, Brazil, 2014.

\begin{tabular}{|c|c|c|c|c|c|c|}
\hline & \multicolumn{3}{|c|}{ Cigarette smoking in life } & \multicolumn{3}{|c|}{ Cigarette use in the last 30 days } \\
\hline & PR & $\mathrm{Cl}$ & p-value ${ }^{1}$ & PR & $\mathrm{Cl}$ & p-value ${ }^{1}$ \\
\hline \multicolumn{7}{|c|}{ Feeling of sadness and suicidal ideation (12 months) } \\
\hline \multicolumn{7}{|c|}{ Feeling Sad } \\
\hline Yes & - & - & - & 1.70 & $1.22-2.36$ & 0.002 \\
\hline No & - & - & - & 1.00 & - & - \\
\hline \multicolumn{7}{|c|}{ Suicidal thoughts } \\
\hline Yes & 1.51 & $1.25-1.82$ & $<0.001$ & - & - & - \\
\hline No & 1.00 & - & - & - & - & - \\
\hline \multicolumn{7}{|c|}{ Use of drugs (30 days) } \\
\hline \multicolumn{7}{|c|}{ Alcohol use } \\
\hline Yes & 1.41 & $1.03-1.92$ & 0.031 & 2.40 & $1.12-5.12$ & 0.024 \\
\hline Não & 1.00 & - & - & 1.00 & - & - \\
\hline \multicolumn{7}{|c|}{ Binge drinking } \\
\hline Yes & 1.57 & $1.15-2.16$ & 0.005 & 2.58 & $1.24-5.38$ & 0.011 \\
\hline No & 1.00 & - & - & 1.00 & - & - \\
\hline \multicolumn{7}{|c|}{ Use of Marijuana use } \\
\hline Yes & 1.64 & $1.37-1.96$ & $<0.001$ & 2.31 & $1.57-3.39$ & $<0.001$ \\
\hline No & 1.00 & - & - & 1.00 & - & - \\
\hline \multicolumn{7}{|c|}{ Cocaine use } \\
\hline Yes & - & - & - & 1.99 & $1.32-3.01$ & 0.001 \\
\hline No & - & - & - & 1.00 & - & \\
\hline \multicolumn{7}{|c|}{ Sexual behavior } \\
\hline \multicolumn{7}{|c|}{ Sexual intercourse } \\
\hline Yes & 1.78 & $1.43-2.21$ & $<0.001$ & - & - & - \\
\hline No & 1.00 & - & - & - & - & - \\
\hline
\end{tabular}

${ }_{1} \mathrm{p}$-value of the Wald statistic. $\mathrm{PR}=$ Prevalence ratio.

The prevalence of cigarette use among adolescents in the city of Olinda was almost 30\%, according to the sample studied, similar to the prevalence observed in Brazil $(30 \%)^{5}$, higher than in the Brazilian Northeast $(15 \%)^{5}$ and in a study in Malaysia ${ }^{11}$.

Regarding the use within the 30 days prior to the survey, our study observed a prevalence of around 10\%, corroborating other studies conducted in Brazil ${ }^{12}$, Malaysia ${ }^{11}$ and Saudi Arabia ${ }^{13}$.

However, cigarette use can trigger and potentiate pathologies, affecting smokers and nonsmokers, who have become passive victims ${ }^{14}$. Hypertension, diabetes, increased risk of developing tuberculosis, premature cutaneous aging, lung cancer, bronchial and tracheal cancer can be cited as damages to health ${ }^{15}$.

There is a concern about these harmful effects of smoking, and various efforts have been made to reduce cigarette use in the world; in Brazil, tobacco restriction has been adopted in both public and private places, prohibition of advertising and fiscal measures such as the increase in tax rates ${ }^{16}$.

In our study, cigarette use both in life and within the 30 days prior to the survey were more prevalent in male adolescents aged 16 years old or more, higher family income and who did not follow a religion, corroborating some of the factors observed by an international study recently conducted ${ }^{13}$.

The adjusted analysis sought to determine the magnitude of the influence of these risk behaviors on smoking. The occurrence of suicidal thoughts, alcohol use, binge drinking, marijuana use, and experiencing sexual intercourse have all been shown to be risk factors for cigarette smoking in their lifetime, and they increase risk by $41 \%$ to $78 \%$ of cigarette 
experimentation in adolescents with this profile. Regarding cigarette use within the 30 days prior to the survey, the risk was increased from $70 \%$ to $158 \%$ in adolescents who admitted having felt sad, used alcohol, binge drinking and having used marijuana and/or cocaine.

Smoking may be considered a non-causal marker of other risk factors for suicide, as well as a marker for mental disorders such as anxiety, depression, and psychosis, or indicate other adverse mental health states such as low self-esteem, behavioral propensity risk, impulsivity, aggressiveness, antisocial personality or emotional instability ${ }^{7}$. Chronic exposure to nicotine reliably reduces serotonin and its metabolites in different brain regions and cerebrospinal fluid ${ }^{17}$. Such reductions in serotonin have been repeatedly linked to increased hostility, aggression and, especially, increased suicide ${ }^{18}$.

Binge drinking in smokers has been associated with increased cigarette smoking ${ }^{5}$ and a greater probability of remaining a smoker ${ }^{19}$. Also, alcohol-dependent individuals who smoke cigarettes consume alcohol with greater quantity and frequency ${ }^{20}$ and are more dependent on alcohol ${ }^{21}$ than those who do not smoke, which agrees with the results of our study. Evidence supports the hypothesis that alcohol enhances the pleasurable effects of nicotine ${ }^{22}$.

There is a hypothesis that the tobacco acts as a drug of passage for the use of marijuana ${ }^{23}$; however, there is also a strong inverse evidence that marijuana consumption predicts the onset of smoking ${ }^{24}$. Several studies suggest explanations for this, for example, that nicotine and marijuana affect similar mesolimbic dopaminergic pathways, suggesting overlapping mechanisms in dependence ${ }^{25}$, as well as shared genetics ${ }^{26}$, temperamental factors ${ }^{27}$, and psychological factors ${ }^{27}$.

Alcohol or tobacco use usually precedes the use of marijuana, which in turn precedes the use of cocaine and other illicit drugs ${ }^{28}$. This connection is consistent with the hypothesis of a sequential model of drug involvement ${ }^{28}$ and with evidence from animal models that suggest that nicotine prepares the induction of particular gene expression to cocaine use ${ }^{29}$.

In a longitudinal study, Garriguet (2005) analyzed the characteristics of adolescents aged 12 and 13 years old who at 14 or 15 years old were involved in sexual activity, stating that having tried to smoke and drink for girls and to smoke for boys were significantly associated with early sexual intercourse ${ }^{30}$, as also observed in our study.

Other aspects commonly related to the use of cigarettes by adolescents include being in the company of smokers, presenting an unfavorable academic profile and aspects related to the family environment and affective relationship with parents ${ }^{31}$. However, the instrument used in this study did not enable to evaluate these aspects in the study population.

Due to the cross-sectional nature of our study, we could not determine a causality between these factors. The health risk behaviors that are most strongly associated with cigarette use in adolescents and that may influence this habit were identified. Further studies focusing on this relationship are necessary, especially studies of longitudinal designs.

Also, considering that adolescence is the second decade of life, a relatively short period in the life of the human being and in which cigarette experimentation generally occurs, it is noted that, when conducting studies with this age group, the questions about "use in life" and "use within the 30 days prior to the survey" can often overlap and constitute the same event. Such imprecision should be pointed as possibly leading to data misinterpretation and subsequent misclassification of adolescents who have only experienced smoking as smoking habits. Therefore, we understand that it is necessary to register more accurately the time elapsed since the experimentation of the cigarette until the moment in which the study is conducted when analyzing the use of cigarettes in adolescents, and if there is, in fact, the habit, as well as the frequency.

Cigarette use among adolescents from Olinda was considered high since it exceeded national and Northeast prevalence. Drug use and behaviors related to sexual experience and feelings 
of sadness and suicidal ideation were the main associated factors observed. Other studies are suggested in compliance with such behaviors to support the development of new public policies to combat smoking, especially to attend to this risk group.

\section{REFERENCES}

1. Instituto Nacional de Câncer; Observatório da Política Nacional de Controle do Tabaco: Prevalência de Tabagismo. Rio de Janeiro: INCA; 2016 [cited 2018 Oct 8]. Available from: http://www2.inca.gov.br/wps/wcm/connect/observatorio_controle_tabaco/site/home/dados_ numeros/prevalencia-de-tabagismo

2. World Health Organization. WHO report on the global tobacco epidemic, 2015: raising taxes on tobacco. Geneva: WHO; 2015.

3. Coutinho RX, Santos WM, Folmer V, Puntel RL. Prevalência de comportamentos de risco em adolescentes. Cad Saude Coletiva. 2013;21(4):441-9. https://doi.org/10.1590/S1414-462X2013000400013

4. Barreto SM, Giatti L, Oliveira-Campos M, Andreazzi MA, Malta DC. Experimentation and use of cigarette and other tobacco products among adolescents in the Brazilian state capitals (PeNSE 2012). Rev Bras Epidemiol. 2014;17 Supl 1:62-76. https://doi.org/10.1590/1809-4503201400050006

5. Instituto Brasileiro de Geografia e Estatística. Pesquisa Nacional de Saúde do Escolar - 2015. Rio de Janeiro: IBGE; 2016.

6. Rosa MI, Caciatori JFF, Panatto APR, Silva BR, Pandini JC, Freitas LBS, et al. Uso de tabaco e fatores associados entre alunos de uma universidade de Criciúma (SC). Cad Saude Coletiva. 2014;22(1):25-31. https://doi.org/10.1590/1414-462X201400010005

7. Chen VCH, Kuo CJ, Wang TN, Lee WC, Chen WJ, Ferri CP, et al. Suicide and othercause mortality after early exposure to smoking and second hand smoking: a 12-year population-based follow-up study. PLoS One. 2015;10(7):e0130044. https://doi.org/10.1371/journal.pone.0130044

8. Guedes DP, Lopes CC. Validação da versão brasileira do Youth Risk Behavior Survey 2007. Rev Saude Publica. 2010;44(5):840-50. https://doi.org/10.1590/S0034-89102010000500009

9. Eaton DK, Kann L, Kinchen S, Shanklin S, Ross J, Hawkins J, et al. Youth Risk Behavior Surveillance-United States, 2007. MMWR Surveill Summ. 2008;57(SS04):1-131.

10. Horta BL, Calheiros P, Pinheiro RT, Tomasi E, Amaral KC. Tabagismo em adolescentes de área urbana na região Sul do Brasil. Rev Saude Publica. 2001;35(2):154-64. https://doi.org/10.1590/S0034-89102001000200009

11. Myint T, Yee MM. Tobacco smoking among school adolescents in Northern Sabah. Asian J Med Biol Res. 2016;2(3):389-95. https://doi.org/ 10.3329/ajmbr.v2i3.30108

12. Bonilha AG, Ruffino-Netto A, Sicchieri MP, Achcar JA, Rodrigues-Júnior AL, Baddini-Martinez J. Correlatos de experimentação e consumo atual de cigarros entre adolescentes. J Bras Pneumol. 2014;40(6):634-42. https://doi.org/10.1590/S1806-37132014000600007

13. Al Agili DE, Park HK. The prevalence and determinants of tobacco use among adolescents in Saudi Arabia. J Sch Health. 2012;82(3):131-8. https://doi.org/10.1111/j.1746-1561.2011.00676.x

14. Iglesias R, Prabhat Jha, Pinto M, Silva VLC, Godinho J. Controle do tabagismo no Brasil. Washington, DC: Banco Mundial; 2007. (Documento de Discussão - Saúde, Nutrição e População).

15. Bojesen SE, Timpson N, Relton C, Smith GD, Nordestgaard BG. AHRR (cg05575921) hypomethylation marks smoking behaviour, morbidity and mortality. Thorax. 2017;72(7):646-53. https://doi.org/10.1136/thoraxjnl-2016-208789

16. Instituto Nacional de Câncer José Alencar Gomes da Silva; Comissão Nacional para Implementação da Convenção-Quadro para Controle do Tabaco (CONICQ). Política Nacional de Controle do Tabaco: relatório de gestão e progresso 2011-2012. Rio de Janeiro: INCA; 2014.

17. Benwell MEM, Balfour DJK, Anderson JM. Smoking-associated changes in the serotonergic systems of discrete regions of human brain. Psychopharmacology. 1990;102(1):68-72. https://doi.org/10.1007/bf02245746

18. Kamali M, Oquendo MA, Mann JJ. Understanding the neurobiology of suicidal behavior. Depress Anxiety. 2001;14(3):164-76. https://doi.org/10.1002/da.1062 
19. Murray RP, Istvan JA, Voelker HT, Rigdon MA, Wallace MD. Level of involvement with alcohol and success at smoking cessation in the Lung Health Study. J Stud Alcohol. 1995;56(1):74-82. https://doi.org/10.15288/jsa.1995.56.74

20. York JL, Hirsch JA. Drinking patterns and health status in smoking and nonsmoking alcoholics. Alcohol Clin Exp Res. 1995;19(3):666-73. https://doi.org/10.1111/j.1530-0277.1995.tb01565.x

21. Daeppen JB, Smith TL, Danko GP, Gordon L, Landi NA, Nurnberger JI Jr, et al. Clinical correlates of cigarette smoking and nicotine dependence in alcohol-dependent men and women. Alcohol Alcohol. 2000;35(2):171-5. https://doi.org/10.1093/alcalc/35.2.171

22. Rose JE, Brauer LD, Behm FM, Cramblett M, Calkins K, Lawhon D. Potentiation of nicotine reward by alcohol. Alcohol Clin Exp Res. 2002;26(12):1930-1. https://doi.org/10.1111/j.1530-0277.2002.tb02507.x

23. Kandel DB, Yamaguchi K, Chen K. Stages of progression in drug involvement from adolescence to adulthood: further evidence for the gateway theory. J Stud Alcohol. 1992;53(5):447-57. https://doi.org/10.15288/jsa.1992.53.447

24. Patton GC, Coffey C, Carlin JB, Sawyer SM, Lynskey M. Reverse gateways? Frequent cannabis use as a predictor of tobacco initiation and nicotine dependence. Addiction. 2005;100(10):1518-25. https://doi.org/10.1111/j.1360-0443.2005.01220.x

25. Filbey FM, Schacht JP, Myers US, Chavez RS, Hutchison KE. Marijuana craving in the brain. Proc Natl Acad Sci USA. 2009;106(31):13016-21. https://doi.org/10.1073/pnas.0903863106

26. Agrawal A, Silberg JL, Lynskey MT, Maes HH, Eaves LJ. Mechanisms underlying the lifetime co-occurrence of tobacco and cannabis use in adolescent and young adult twins. Drug Alcohol Depend. 2010;108(1-2):49-55. https://doi.org/10.1016/j.drugalcdep.2009.11.016

27. Brook JS, Lee JY, Finch SJ, Brown EN. Course of comorbidity of tobacco and marijuana use: psychosocial risk factors. Nicotine Tob Res. 2010;12(5):474-82. https://doi.org/10.1093/ntr/ntq027

28. Kandel D, Kandel E. The Gateway Hypothesis of substance abuse: developmental, biological and societal perspectives. Acta Paediatr. 2015;104(2):130-7. https://doi.org/10.1111/apa.12851

29. Kandel ER, Kandel DB. A molecular basis for nicotine as a gateway drug. N Engl J Med. 2014;371(21):932-43. https://doi.org/10.1056/NEJMsa1405092

30. Garriguet D. Early sexual intercourse. Health Rep. 2005;16(3):9-18.

31. Coutinho EC, Pestana L, Duarte JC, Amaral O, Nelas P, Chaves C, et al. Tobacco consumption in adolescents and school performance. Aten Primaria. 2016;48 Suppl C:266-70.

Funding: This study was financed in part by the Coordenação de Aperfeiçoamento de Pessoal de Nível Superior - Brasil (CAPES) - Finance Code 001.

Authors' Contribution: Study conception and planning: VC, VAM, CFBFS. Data collection: JFC, PAMV. Data analysis and interpretation: JFC, VC, CFBFS. Manuscript writing: JFC, PAMV, VC. Review of the manuscript: VC, PMPAZ, JLL.

Conflict of Interest: The authors declare no conflict of interest. 